\title{
Antenatal Diagnosis and Management of Conjoined Twins: A case Report
}

\author{
de Silva R S ${ }^{1}$, Amaradivakara P W ${ }^{2}$
}

\section{INTRODUCTION}

Conjoined twins accounts for a very rare entity in obstetric practice. Incidence of conjoined twins varies between one in 50000 to one in 100000 worldwide ${ }^{1-4}$. There is pictorial evidence of conjoined twins as far as 1100 AD where "Biddenden Maids" were lived in Biddenden, Kent, UK. They were lived until the age of 34 ${ }^{3}$. But a well known conjoined twins named as "Siamese Twins" were born in Thailand in 1811 and known to lived 69 years and after which Siamese twins is used as a synonym for Conjoined twins 3,5,6. Although first antenatal diagnosis of conjoined twins reported in year 1970 by using B-mode ultrasound it is currently possible without difficulty by using 2D and 3D ultrasound facilities ? Antenatal detection of Conjoined twins is of paramount importance as it provides wide range of management options. Termination of pregnancy can be considered after careful counseling where legal provisions are available ${ }^{7}$. As Sri Lankan Law does not allow termination of pregnancy for fetal malformations Sri Lankan parents will not be given that option. Therefore antenatal diagnosis of even unsalvageable forms of conjoined twins will not be offered termination. Depending on the form of fusion and organ sharing separation can be considered after delivery. Best outcome is achieved by elective separation but in some circumstances emergency separation is required ${ }^{1}$.

Registrar In Obstetrics and Gynaecology, TH MAHAMODARA.

Consultant Obstetrician and Gynaecologist, TH MAHAMODARA.

Correspondence: Dr Priyankari Amaradivakara

E-mail: pamaradivakara@ hotmail.com

Competing interests: None

\section{CASE}

Mrs JL, 38 year old mother of three children who booked late at $28^{\text {th }}$ week of POA was referred for tertiary care clinic at $32^{\text {nd }}$ week of POA. All three children were born vaginally and the age of the last child was six years. She has had a proper follow up during her previous pregnancies and she was not detected to have significant problems in past pregnancies. She was not on a proper contraceptive method after her last pregnancy which has resulted unexpected index pregnancy. She was not on folic acid therapy until $28^{\text {th }}$ week of POA at which she was booked at $\mathrm{MOH}$ clinic. Her weight at booking was $73 \mathrm{~kg}$. Blood pressure was $110 / 70 \mathrm{mmHg}$ at booking. Symphysio- fundal height was $36 \mathrm{~cm}$ and found incompatible to the POA of 28 week. Post prandial blood glucose, hemoglobin and urine analysis done at booking were in normal range. Her marriage was not consanguineous. She and her husband did not give a history of exposure to teratogenic substances.

She attended our antenatal clinic at $32^{\text {nd }}$ week of POA. Weight at booking was $75 \mathrm{~kg}$. Blood pressure was 120/70 $\mathrm{mmHg}$ and Symphysio-fundal height was $41 \mathrm{~cm}$. Abdominal examination suggested twin pregnancy with first twin in cephalic presentation. Basic urine analysis was normal.

Ultrasound examination revealed conjoined twins joined in the abdomen and pelvis (Ischio-omphalopagus). Two separate heads were seen with one head in the lower pole and one in transverse position. Transverse position head showed severe ventriculomegaly with atrophied brain matter. Head circumferences of two heads were compatible with 30 weeks and 40 weeks respectively. Skull base vasculatures and facial structures of both heads were normal. Two separate hearts were seen. Both hearts contained four ventricles each. Two separate thoraces were noted with two independent thoracic aortae. Each twin had an independent pair of lungs but in transverse twin mild to moderate degree of lung hypoplasia was seen. One large liver has seen sharing among both twins. But they had two separate diaphragms separating common liver form two thoraces. One bladder identified. Two kidneys were seen. Abdominal circumferences of cephalic twin and transverse twin were compatible with 30 weeks and 28 weeks respectively. Four upper limbs were identified. Lower limbs were difficult to visualize. Only two lower limbs were visualized. Only one site of cord insertion could be seen. Placenta was fundal in position. Liquor volume was satisfactory with AFI of $12 \mathrm{~cm}$ with deepest pool measuring $4.7 \mathrm{~cm}$. Umbilical artery Doppler indices were normal according to the POA.

Mother and relations were explained the condition and counseling was done with regard to possible poor prognosis. Mother refused an option of proper fetal medicine ultrasound analysis and in-utero transfer to Colombo. Multidisciplinary team approach was made involving Obstetrician, Paediatric and paediatric surgical inputs. Course of steroids was given. Delivery by elective caesarean section and ligation \& resection of tubes was planned at 36 completed weeks.

Elective caesarean section was done at 36 completed weeks. Pfannenstiel incision and lower segment transverse uterine incision were used. Conjoined twins were carefully delivered. Combined weight was $4.100 \mathrm{~kg}$ and of female sex. APGAR scores of 1 and 5 minutes of cephalic twin and transverse twin were $7 / 10,10 / 10$ and $4 / 10,8 / 10$ respectively. They were Ischiopagus twins and fused to each other by pelvis and abdomen. One co-twin had a hydrocephalic head and other co-twin had a normal head. All facial structures were normal. There 
were two separate sets of upper limbs. Two lower limbs of the co-twin with a hydrocephalic head were fused together. Lower limbs of other co-twin were free. They had single anal orifice but two separate introituses, external urethral orifices and vaginae.

Conjoined twins were handed over to the Paediatric team and subsequently transferred to Paediatric surgical team at $\mathrm{TH}$ Karapitiya. Further investigations revealed that co twin with hydrocephalic head had a malfunctioning heart and depends on the circulation of the other twin who was salvageable. They faced emergency separation at the age of two months due to deteriorating cardiac function of the salvageable twin. At the surgery healthy co twin was salvaged in the expense of scarification of other co-twin.

\section{Fig 1. Ischiopagus conjoined twins soon after delivery}

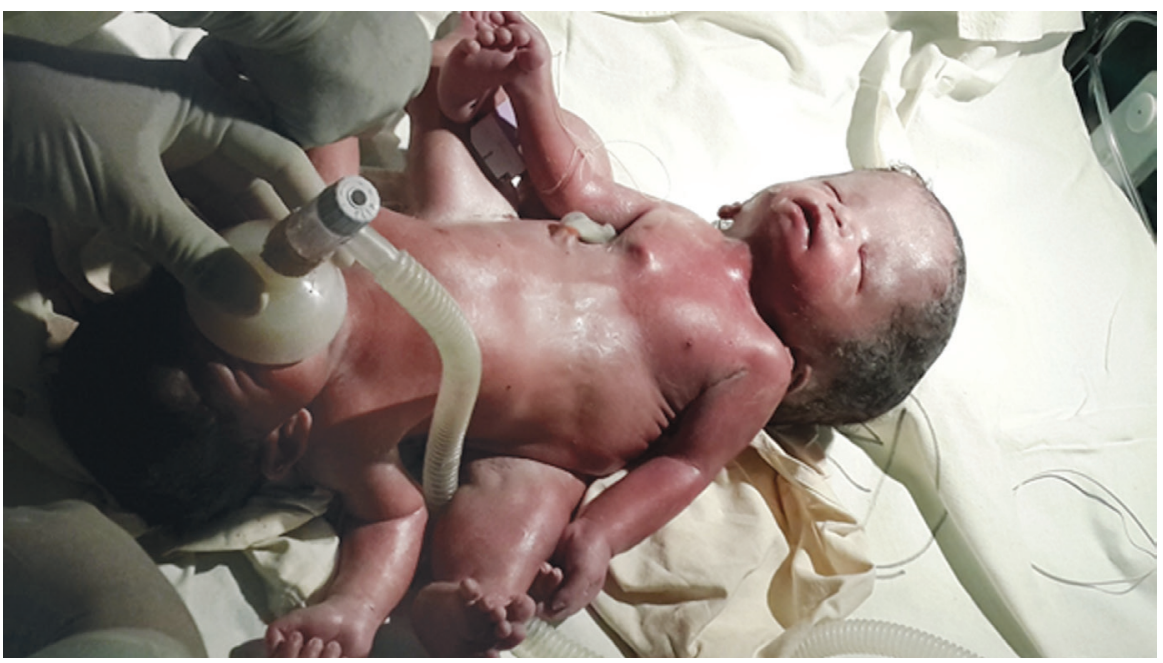

\section{DISCUSSION}

\section{Classification}

The classification of conjoined is according to the site of fusion. Sites of fusion in both twins are almost always identical ${ }^{1}$. The term "pagus" is used to denote the fusion. Omphalopagus means that they are joined form the ventral surface of the trunk. They face each other and usually joined to various degrees from xiphoid to umbilicus. Commonly they share a single liver or two livers fused by a bridge. Gastrointestinal tracts show various degree of sharing. Thoracopagus twins unite by their chest. They also face each other and

commonly share a single sternum, diaphragm, rib cage and anterior abdominal wall with varying degrees. Majority share a single heart. Some times two separate hearts may lie in a common pericardium. Various degrees of congenital anomalies in the cardiovascular system are common. Omphalo-thoracopagus twins are joined with both their chest and abdomen and show various degrees of sharing seen in thoracopagus and omphalopagus group. Pygopagus twins join in the gluteal region with the fusion of sacrum. They face away from each other and commonly have single sacral spinal cord and single anus, rectum bladder and urethra. Ischiopagus twins are joined by their pelvis and usually share pelvic organs and liver. Craniopagus twins are joined by their skull with 
unusual extension of the fetal spines, unusual proximity of fetal extremities and constant fetal positions to one another ${ }^{3,9,10}$. MRI scan is helpful in assessing detailed anatomy ${ }^{4}$. Serum markers are not helpful but serum alpha-fetoproteins level is reported to be elevated in some cases ${ }^{3}$. The main objective of antenatal diagnosis is to evaluate the viability of twins and potential surgical separation after birth 1,3,4. Detail systemic ultrasonic assessment is required and opinion of a fetal medicine specialist should be sought with this regard.

\section{Antenatal management}

The main objectives with this regard are optimizing the maturity of twins, prevention of preterm labour, identifying fetal compromise and minimizing maternal morbidity. There is a high risk of death in utero compared to dichorionic twin pregnancy ${ }^{11}$. Corticosteroids may be administered to optimize the lung maturity ${ }^{11}$. Exact fetal monitoring protocols for conjoint twins are lacking. Maternal morbidity should be monitored and managed as in a twin pregnancy. Uncomplicated pregnancies can be continued until 36 weeks ${ }^{11}$. Mode of delivery is by elective caesarean section although vaginal deliveries of conjoined twins were recorded 1,2,12. Delivery should be planned with the support of a multidisciplinary team involving Obstetrician, Neonatologist, Pediatric surgeon and Pediatric anesthetist 1,5. Neonatal resuscitation facilities must be present at the time of delivery. If neonatal intensive care facilities and pediatric surgical facilities are not available in utero transfer to a suitable centre is a better option as emergency separation may be required depending on the status of twins after delivery.

\section{CONCLUSION}

Conjoined twining is a rare condition of which exact aetiology is uncertain. Proper antenatal diagnosis is important as it enables wide range of management options. Ultrasound scan is the primary tool of diagnosis and MRI scan will help evaluating detail anatomy. For unsalvageable conjoined twins termination of pregnancy is an option whereas for salvageable twins elective delivery and subsequent surgical separation is preferable. Careful counseling is paramount throughout the management and decisions. Parent's views should always be considered in the management. During antenatal period maternal morbidity and fetal compromise should be minimized. Uncomplicated cases can be continued until 36 weeks. Multidisciplinary team approach is necessary to plan delivery \& further management. If facilities are lacking in utero transfer should be considered.

\section{REFERENCES:}

1. Rode H, Fieggen AG, Brown RA, Cywes $S$, Davies MRQ. Four decades of conjoined twins at Red Cross Children's Hospital - lessons learned. South african Medical Journal 2006;96(9):931-940

2. Cetin O, Kurdoglu Z, Cim N, Yildizhan R, Sahin G, Kurdoglu M.Early Prenatal Diagnosis of Conjoined Twins: Case Series. International Journal of Women's Health and Reproduction Sciences 2015;3(3): 168-170

3. Athanasiadis A, Mikos T, Zafrakas M. Prenatal Diagnosis and Management of Conjoined Fetuses. Donald School Journal of Ultrasoud in Obstetrics and Gynecology 2007;1(1):96-104
4. Ayhan O, Karaca M, Ahmet G, Bayram $\mathrm{M}$, Akif S. Cephalopagus conjoined twins presented with encephalocele: diagnostic role of ultrafast MR imaging. Diagn Interv Radiol 2006; 12:90-92

5. Suriyarachch CP. Surgical experience with conjoined twins. Sri Lanka Journal of Child Health 2010; 39: 64-66

6. Tannuri ACA, Batatinha JAP, Velhote MCP, Tannuri U. Conjoined twins - twenty years' experience at a reference center in Brazil. CLINICS 2013;68(3):371-377

7. Kirbas A, Biberoglu E, Celen S, Oztas E, Uygur D, Danisman N. A case of thoracopagus conjoined twins. 13th world congress of Fetal Medicine, Nice, France 2014

8. Sharma UK, Dagol A, Chawla CD, Shrestha D. Antenatal Detection of Conjoined Twin. J Nepal Med Assoc 2007;46(167):133-135

9. Harma M, Mil Z, Oksuzler C. Vaginal Delivery of Dicephalic Parapagus Conloined Twins: Case Report an Litreture Review. Tohoku J Exp Med 2005;205:179-185

10. Morin L, Lim K.Ultrasound in Twin Pregnancies. SOGC Clinical Practice Guideline No 260, 2011 June

11. Green-top guideline No 51. Management Of Monochorionic Twin Pregnancy. 2008 December

12. Cuillier F, Dillon KC, Grochal F, Scemama JM, Gervais T, Cerekja A, Piazze J. Conjoined twins: what ultrasound may add to management. Journal of Prenatal Medicine 2012; 6 (1): 4-6 